\title{
International Retrospective Study of the Pipeline Embolization Device: A Multicenter Aneurysm Treatment Study
}

\author{
D.F. Kallmes, R. Hanel, D. Lopes, E. Boccardi, A. Bonafé, S. Cekirge, D. Fiorella, P. Jabbour, E. Levy, C. McDougall, A. Siddiqui, I. Szikora, \\ H. Woo, F. Albuquerque, H. Bozorgchami, S.R. Dashti, J.E. Delgado Almandoz, M.E. Kelly, R. Turner IV, B.K. Woodward, W. Brinjikji,
}

G. Lanzino, and P. Lylyk

\begin{abstract}
BACKGROUND AND PURPOSE: Flow diverters are increasingly used in the endovascular treatment of intracranial aneurysms. Our aim was to determine neurologic complication rates following Pipeline Embolization Device placement for intracranial aneurysm treatment in a real-world setting.
\end{abstract}

MATERIALS AND METHODS: We retrospectively evaluated all patients with intracranial aneurysms treated with the Pipeline Embolization Device between July 2008 and February 2013 in 17 centers worldwide. We defined 4 subgroups: internal carotid artery aneurysms of $\geq 10 \mathrm{~mm}$, ICA aneurysms of $<10 \mathrm{~mm}$, other anterior circulation aneurysms, and posterior circulation aneurysms. Neurologic complications included spontaneous rupture, intracranial hemorrhage, ischemic stroke, permanent cranial neuropathy, and mortality. Comparisons were made with $t$ tests or ANOVAs for continuous variables and the Pearson $\chi^{2}$ or Fisher exact test for categoric variables.

RESULTS: In total, 793 patients with 906 aneurysms were included. The neurologic morbidity and mortality rate was $8.4 \%$ (67/793), highest in the posterior circulation group $(16.4 \%, 9 / 55)$ and lowest in the ICA $<10-\mathrm{mm}$ group $(4.8 \%, 14 / 294)(P=.01)$. The spontaneous rupture rate was $0.6 \%$ (5/793). The intracranial hemorrhage rate was $2.4 \%$ (19/793). Ischemic stroke rates were $4.7 \%(37 / 793)$, highest in patients with posterior circulation aneurysms $(7.3 \%, 4 / 55)$ and lowest in the ICA $<10-\mathrm{mm}$ group $(2.7 \%, 8 / 294)(P=.16)$. Neurologic mortality was $3.8 \%$ (30/793), highest in the posterior circulation group $(10.9 \%, 6 / 55)$ and lowest in the anterior circulation ICA $<10-\mathrm{mm}$ group $(1.4 \%, 4 / 294)(P<$ .01).

CONCLUSIONS: Aneurysm treatment with the Pipeline Embolization Device is associated with the lowest complication rates when used to treat small ICA aneurysms. Procedure-related morbidity and mortality are higher in the treatment of posterior circulation and giant aneurysms.

ABBREVIATIONS: IntrePED = International Retrospective Study of Pipeline Embolization Device; IPH = intraparenchymal hemorrhage; PED = Pipeline Embolization Device

Endoluminal flow-diverter therapy has gained widespread acEceptance for the treatment of intracranial aneurysms. ${ }^{1-4}$ High rates of complete aneurysm occlusion have been reported, even in

Received March 27, 2014; accepted after revision June 23.

From the Department of Radiology (D.F.K., W.B., G.L.), Mayo Clinic, Rochester, Minnesota; Department of Neurosurgery (R.H.), Mayo Clinic, Jacksonville, Florida; Department of Neurological Surgery (D.L.), Rush University Medical Center, Chicago, Illinois; Department of Neuroradiology (E.B.), Niguarda CA' Granda Hospital, Milan, Italy; Department of Neuroradiology (A.B.), Hôpital Gui de Chauliac, Montpellier,

France; Department of Radiology (S.C.), Hacettepe University Hospitals, Ankara,

Turkey; Department of Neurological Surgery (D.F., H.W.), Stony Brook University

Medical Center, Stony Brook, New York; Department of Neurosurgery (P.J.),

Thomas Jefferson University, Philadelphia, Pennsylvania; Department of Neurosurgery (E.L., A.S.), University at Buffalo, State University of New York, Buffalo, New York; Department of Neurosurgery (C.M., F.A.), Barrow Neurological Associates, Phoenix, Arizona; National Institute of Neurosciences (I.S.), Budapest, Hungary; Department of Neurology (H.B.), Oregon Health and Science University, Portland, Oregon; Norton Neuroscience Institute (S.R.D.), Louisville, Kentucky; Department of Radiology (J.E.D.A.), Neuroscience Institute, Abbott Northwestern Hospital, Minneapolis, Minnesota; Division of Neurosurgery, Department of Surgery (M.E.K.), University of Saskatchewan, Saskatoon, Saskatchewan, Canada; large and giant aneurysms, with the use of endoluminal flow diverters. ${ }^{1-7}$ The Pipeline Embolization Device (PED; Covidien, Irvine, California) received CE mark approval in 2008 for the embolization of cerebral aneurysms and received US FDA approval in 2011 (PMA P100018) for the treatment of large and giant wideneck aneurysms in the internal carotid artery, from the petrous to the superior hypophyseal segments. While numerous previous studies have reported overall rates of adverse events similar to

Department of Neurosciences (R.T.), Medical University of South Carolina, Charleston, South Carolina; Vista Radiology PC (B.K.W.), Knoxville, Tennessee; and Department of Neuroscience (P.L.), Equipo de Neurocirugía Endovascular Radiología Intervencionista, Buenos Aires, Argentina.

Preliminary results of this study previously presented at: Annual Meeting of the Society of Neurolnterventional Surgery, July 29-August 1, 2013; Miami, Florida.

Please address correspondence to David Kallmes, MD, Mayo Clinic, 200 First St SW, OL1-112 SMH, Rochester, MN 55905; e-mail: Kallmes.david@mayo.edu

$\equiv$ Indicates article with supplemental on-line appendix.

http://dx.doi.org/10.3174/ajnr.A4111 
those in other endovascular procedures, case reports and small case series documenting severe and "unexpected" complications have raised questions about the safety of these devices. ${ }^{1,3,8,9} \mathrm{Se}-$ vere and unexpected adverse events include spontaneous rupture of treated aneurysms and intraparenchymal intracranial hemorrhage unrelated to aneurysm rupture. ${ }^{8,10-12}$ These reports led to policies in some regions mandating concomitant coil embolization with flow-diverter therapy to mitigate the risk of spontaneous aneurysm rupture. ${ }^{13}$

Most previous literature on flow-diversion therapy comprised single-center case series, either retrospective or prospective, and has substantial selection bias, which may affect the rates of severe and unexpected adverse events. These biases may be diminished through pooling of consecutive patients treated at multiple centers in a "real-world" setting, with homogeneous end points and methods of data analysis. The International Retrospective Study of Pipeline Embolization Device (IntrePED) registry was designed for this purpose and to determine rates of important neurologic safety events following PED placement for intracranial aneurysm treatment.

\section{MATERIALS AND METHODS Study Design and Participants}

We retrospectively evaluated all patients with intracranial aneurysms treated with the Pipeline Embolization Device between July 2008 and February 2013 in 6 countries in 17 centers experienced in PED use. Local institutional review boards or ethics committees approved the study and use of patients' retrospective data. An institutional review board/ethics committee waiver of informed consent (and Health Insurance Portability and Accountability Act Waiver of Authorization for US sites) or a sponsor institutional review board/ethics committee-approved informed consent form was obtained from each participating site. Written informed consent was obtained from each patient, if required. This observational registry was funded and supported by Covidien, with scientific oversight of the study steering committee members. Physicians who contributed data for this study were endovascular-trained neurointerventionalists. Each site that participated was required to have at least 1 physician who had treated a minimum of 10 PED cases before the time of institutional review board/ethics committee approval for the study. Unless an investigator had been a participant in a clinical study before commercialization of the PED, this study captures the investigators' experience as new users of the device. A majority of the 26 IntrePED physicians were new users, and their early cases were included in the registry.

Data were collected from the time of the first commercial use of PED at a site until the time of institutional review board/ethics committee approval of the study protocol for that site. Investigational centers were required to provide data on all consecutive patients to eliminate selection bias, provided that the patients fulfilled the following conditions: 1) received PED treatment for an intracranial aneurysm after the date of regulatory approval in that region or country, and 2) had a clinical evaluation following treatment during the window of time before institutional review board/ethics committee approval. Because this was a retrospective study, there were no patients lost to follow-up.
Seven hundred ninety-three patients treated for 906 aneurysms were enrolled. Many patients (38\%) had been previously reported in the literature. ${ }^{14-29}$ We defined 4 primary anatomic/ size subgroups: internal carotid artery aneurysms $\geq 10 \mathrm{~mm}$ ("large ICA"), ICA aneurysms of $<10 \mathrm{~mm}$ ("small ICA"), other anterior circulation aneurysms ("other anterior"), and posterior circulation aneurysms.

\section{Procedures}

Because this was a retrospective study, procedural details and periprocedural patient management varied across centers. All centers used a common study protocol that specified the data to be collected, study end points, events of interest, and statistical analyses. The Steering Committee defined neurologic "clinical safety events of interest" a priori, including spontaneous rupture of the target aneurysm causing subarachnoid hemorrhage or cavernous carotid fistula, intraparenchymal hemorrhage (IPH) (both ipsilateral and contralateral), ischemic stroke, parent artery stenosis, and permanent cranial neuropathy. Site investigators identified events of interest according to the study protocol through retrospective review of the patient's record. All events of interest were reviewed in detail by an Adverse Events Review Committee, comprising of 3 members of the Steering Committee, including the overall study principal investigator. The committee determined the category of event and whether the event was major or minor. A "major" adverse event was defined as an ongoing clinical deficit at 7 days following the event. "Minor" adverse events were defined as events that resolved within 7 days with no clinical sequelae. All major adverse events are included in the neurologic morbidity and mortality rates. Long-term neurologic morbidity and mortality rates included morbidity and mortality due to adverse events occurring any time in the postoperative period ( $<30$ days and $\geq 30$ days). Information collected during the study was standardized across centers and included baseline characteristics of patients and aneurysms, procedural information, prespecified clinical safety events of interest, and follow-up clinic visits or telephone calls. A list of data collected for each patient/aneurysm is provided in the On-line Appendix. Because this was a retrospective study, the timing of the patient follow-up evaluations was conducted per institution standard of care.

\section{Statistical Analysis}

Statistical analyses were performed by using SAS, Version 9.1 or higher (SAS Institute, Cary, North Carolina). Summary statistics are presented for all data available by using means and SDs for continuous variables and frequency tabulations for categoric variables. Comparisons between groups for continuous variables were evaluated by using $t$ tests or ANOVAs and the Fisher exact test or Pearson $\chi^{2}$ for binary categoric variables. Most statistical analyses were performed across patient groups- that is, on a perpatient basis. Because some patients had $>1$ aneurysm treated with a PED, however, each patient's first aneurysm was used to classify patients into the 4 anatomic/size subgroups, and the largest aneurysm was used to classify patients into the 3 aneurysm size categories. Some analyses, including aneurysm characteristics and spontaneous ruptures across aneurysm-size groups, were performed across all aneurysms rather than across patients.

AJNR Am J Neuroradiol 36:108-15 Jan 2015 www.ajnr.org 


\begin{tabular}{|c|c|c|c|c|c|c|}
\hline Aneurysm Characteristics & $\begin{array}{c}\text { Anterior ICA } \\
\geq 10 \mathrm{~mm}(n=311)\end{array}$ & $\begin{array}{c}\text { Anterior } \\
<10 \mathrm{~mm}(n=349)\end{array}$ & $\begin{array}{l}\text { Posterior } \\
(n=59)\end{array}$ & $\begin{array}{l}\text { Other Anterior } \\
\geq 10 \mathrm{~mm}(n=178)\end{array}$ & Total $(n=896)^{a}$ & $\begin{array}{c}P \\
\text { Value }\end{array}$ \\
\hline \multicolumn{7}{|l|}{ Aneurysm size (mm) } \\
\hline Mean \pm SD & $16.8 \pm 6.2$ & $5.2 \pm 2.2$ & $14.5 \pm 9.0$ & $9.8 \pm 7.9$ & $10.7 \pm 7.7$ & $<.001$ \\
\hline Median, range & $15.0,10.0-42.0$ & $5.0,1.0-9.9$ & $11.8,1.7-45.0$ & $7.2,1.0-55.0$ & $9.0,1.0-55.0$ & \\
\hline \multicolumn{7}{|l|}{ Aneurysm type } \\
\hline Small & 0 & $349 / 349(100 \%)$ & $19 / 58(32.8 \%)$ & $105 / 178(59.0 \%)$ & $473 / 897(52.8 \%)$ & \\
\hline Large & $268 / 311(86.2 \%)$ & 0 & $29 / 58(50.0 \%)$ & $60 / 178(33.7 \%)$ & $357 / 897(39.8 \%)$ & \\
\hline Giant & $43 / 311(13.8 \%)$ & 0 & $10 / 58(17.2 \%)$ & $13 / 178(7.3 \%)$ & $66 / 897(7.3 \%)$ & \\
\hline \multicolumn{7}{|l|}{ Aneurysm neck (mm) } \\
\hline Mean \pm SD & $8.5 \pm 5.1$ & $4.1 \pm 2.2$ & $9.3 \pm 8.4$ & $5.3 \pm 5.1$ & $6.2+4.9$ & $<.001$ \\
\hline Median, range & $7.6,0.9-50.0$ & $4.0,0.8-22.0$ & $8.0,1.7-53.0$ & $4.0,1.0-50.0$ & $5.0,0.8-53.0$ & \\
\hline \multicolumn{7}{|l|}{ Aneurysm shape } \\
\hline Fusiform & 49/311 (15.8\%) & $17 / 349(4.9 \%)$ & $17 / 59(28.8 \%)$ & 29/178 (16.3\%) & $112 / 897(12.5 \%)$ & $<.001$ \\
\hline Saccular & 239/311 (76.9\%) & $305 / 349(87.4 \%)$ & $25 / 59(42.4 \%)$ & $118 / 178(66.3 \%)$ & $686 / 897(76.5 \%)$ & \\
\hline Dissecting & $10 / 311(3.2 \%)$ & $8 / 349(2.3 \%)$ & $13 / 59(22.0 \%)$ & $22 / 178(12.4 \%)$ & $53 / 897(5.9 \%)$ & \\
\hline Other & $13 / 311(4.2 \%)$ & $19 / 349(5.4 \%)$ & $4 / 59(6.8 \%)$ & $9 / 178(5.1 \%)$ & $46 / 897(5.1 \%)$ & \\
\hline \multicolumn{7}{|l|}{ Aneurysm location } \\
\hline Internal carotid artery & $311 / 311(100 \%)$ & $349 / 349(100 \%)$ & 0 & 0 & $660 / 897(73.6 \%)$ & $<.001$ \\
\hline Middle cerebral artery & 0 & 0 & 0 & $43 / 178$ (24.2\%) & $43 / 897(4.8 \%)$ & \\
\hline Posterior cerebral artery & 0 & 0 & $15 / 59(25.4 \%)$ & 0 & $15 / 897(1.7 \%)$ & \\
\hline Basilar artery & 0 & 0 & $44 / 59(74.6 \%)$ & 0 & $44 / 897$ (4.9\%) & \\
\hline Other & 0 & 0 & 0 & $135 / 178(75.8 \%)$ & $135 / 897(15.1 \%)$ & \\
\hline Presented with ruptured aneurysm & $12 / 311(3.9 \%)$ & $24 / 345$ (7.0\%) & $4 / 59(6.8 \%)$ & $34 / 176(19.3 \%)$ & $74 / 891(8.2 \%)$ & $<.001$ \\
\hline Multiple PEDs used & $143 / 311(46.0 \%)$ & $97 / 347(28.0 \%)$ & $19 / 59(32.2 \%)$ & $47 / 178(26.4 \%)$ & $306 / 895(34.2 \%)$ & $<.001$ \\
\hline
\end{tabular}

Note: $-n$ indicates the number of aneurysms.

${ }^{a}$ Aneurysm size was not reported for 10 aneurysms.

\section{Role of the Funding Source}

An academic principal investigator and an academic steering committee supervised the trial design and operations. The steering committee interpreted the results, and the principal investigator wrote the report. The study sponsor was responsible for site management, data management, statistical analysis, and safety reporting. The corresponding author was the academic principal investigator for the study and had full access to all study data and the final responsibility for the decision to submit for publication.

\section{RESULTS}

Seven hundred ninety-three patients with 906 aneurysms (76 [8.4\%] ruptured, 824 [91\%] unruptured, and 6 [0.7\%] unknown) were included. Three hundred eleven aneurysms (34.3\%) were ICA $\geq 10 \mathrm{~mm}, 349$ aneurysms $(38.5 \%)$ were ICA $<10 \mathrm{~mm}, 59$ aneurysms $(6.5 \%)$ were in the posterior circulation, and 178 aneurysms $(19.6 \%)$ were $\geq 10 \mathrm{~mm}$ and located in anterior circulation locations other than the ICA. Combined location/size information was not available for 9 aneurysms. Posterior circulation aneurysms were generally large, with an average size of $14.5 \pm 9.0$ $\mathrm{mm}$. Patients with non-ICA anterior circulation aneurysms presented with aneurysm rupture in $19.3 \%$ of cases $(34 / 176)$, a significantly higher rate than that in the other groups $(P<.001)$. Four hundred seventy-three aneurysms (52.8\%) were small, 357 aneurysms (39.8\%) were large, and 66 aneurysms (7.3\%) were giant. Median follow-up was 19.3 months with 706 (89\%) patients having follow-up of $>12$ months. Size information was not available for 10 aneurysms.

Multiple PEDs were used in 308 cases (34.2\%). Patients with ICA aneurysms $\geq 10 \mathrm{~mm}$ had the highest rate of multiple PED use $(46.0 \%, 143 / 311)$ and were significantly more likely to receive treatment with multiple PEDs compared with the other groups $(P<.001)$. Mean procedure time was 101 minutes 30 seconds \pm
50 minutes 30 seconds and was highest in the ICA aneurysms $\geq 10$-mm group (111 minutes 24 seconds \pm 56 minutes $36 \mathrm{sec}$ onds) $(P<.01)$. Aneurysm data are summarized in Table 1.

The 30-day morbidity and mortality rate was $6.3 \%(50 / 793)$ with a 30-day neurologic morbidity rate of 5.7\% (44/793) and a 30 -day neurologic mortality rate of $2.6 \%$ (21/793). The long-term neurologic morbidity and mortality rate was $8.4 \%$ (67/793) with a neurologic morbidity rate of $7.4 \%(59 / 793)$ and a neurologic mortality rate of $3.8 \%$ (30/793). Individual morbidity and mortality rates did not add up to the total combined morbidity and mortality rate because some patients had $>1$ neurologic morbidity. The morbidity and mortality rates were highest in the posterior circulation group $(16.4 \%, 9 / 55)$ and lowest in the ICA $<10$ mm group $(4.8 \%, 14 / 294)$. The morbidity and mortality rates were higher in patients with giant aneurysms compared with those with large and small aneurysms $(25.8 \%$ versus $8.8 \%$ versus $5.4 \%, P<.01)$. When patients with ruptured, dissecting, or fusiform aneurysms were excluded, the overall morbidity and mortality rate was $5.7 \%$.

The spontaneous rupture rate was $0.6 \%$ (5/793), with 2 of the 5 events being cavernous carotid fistulas with clinical sequelae. Four of the 5 cases occurred within 30 days. There was no difference in the spontaneous rupture rate among the 4 groups $(P=$ .17). Spontaneous rupture was higher in giant aneurysms $(4.5 \%$, $3 / 66)$ compared with large $(0.6 \%, 2 / 357)$ and small aneurysms $(0.0 \%, 0 / 473)(P<.001)$. Overall the intraparenchymal hemorrhage rate was $2.4 \%(19 / 793)$. There was no difference in the hemorrhage rate among the primary patient subgroups $(P=.73)$ or among aneurysm sizes $(P=.24)$. Fifteen $(79 \%)$ of the 19 hemorrhages occurred within 30 days of the procedure.

The ischemic stroke rate was $4.7 \%$ (37/793). A majority of strokes occurred within 30 days of treatment $(26 / 793,3.3 \%)$. The 
Table 2: Complications by aneurysm location and size subgroups

\begin{tabular}{|c|c|c|c|c|c|c|}
\hline Complications & $\begin{array}{c}\text { Anterior ICA } \\
\geq 10 \mathrm{~mm}(n=275)\end{array}$ & $\begin{array}{c}\text { Anterior ICA } \\
<10 \mathrm{~mm}(n=294)\end{array}$ & $\begin{array}{l}\text { Posterior } \\
(n=55)\end{array}$ & $\begin{array}{l}\text { Other Anterior } \\
\qquad(n=165)\end{array}$ & $\begin{array}{c}\text { Total } \\
(n=793)^{a}\end{array}$ & $\begin{array}{l}95 \% \mathrm{Cl} \\
P \text { Value }\end{array}$ \\
\hline Mean aneurysm size $(\mathrm{mm})$ & $16.8 \pm 6.2$ & $5.2 \pm 2.2$ & $14.5 \pm 9.0$ & $9.8 \pm 7.9$ & $10.7 \pm 7.7$ & $(10.2-11.2) ;<.001$ \\
\hline Spontaneous rupture & $4(0.7 \%)$ & $0(0.0 \%)$ & $0(0.0 \%)$ & $1(0.6 \%)$ & $5(0.6 \%)$ & $(0.2 \%-1.5 \%) ; .17$ \\
\hline Intraparenchymal hemorrhage & $6(2.2 \%)$ & $6(2.0 \%)$ & $1(1.8 \%)$ & $6(3.6 \%)$ & $19(2.4 \%)$ & $(1.3 \%-3.4 \%) ; .73$ \\
\hline Ischemic stroke & $15(5.5 \%)$ & $8(2.7 \%)$ & $4(7.3 \%)$ & $10(6.1 \%)$ & $37(4.7 \%)$ & $(3.2 \%-6.2 \%) ; .16$ \\
\hline Parent artery stenosis & $1(0.4 \%)$ & $1(0.4 \%)$ & $0(0.0 \%)$ & $0(0.0 \%)$ & $2(0.3 \%)$ & $(0 \%-0.7 \%) ; 1.0$ \\
\hline Cranial neuropathy & $2(0.7 \%)$ & $0(0.0 \%)$ & $0(0.0 \%)$ & $0(0.0 \%)$ & $2(0.3 \%)$ & $(0 \%-0.7 \%) ; .30$ \\
\hline Neurologic morbidity & $24(8.7 \%)$ & $14(4.5 \%)$ & $5(9.1 \%)$ & $16(9.7 \%)$ & $59(7.4 \%)$ & $(5.6 \%-9.2 \%) ; .16$ \\
\hline Neurologic mortality & $11(4.0 \%)$ & $4(1.4 \%)$ & $6(10.9 \%)$ & $9(5.5 \%)$ & $30(3.8 \%)$ & $(2.5 \%-5.1 \%) ;<.01$ \\
\hline $\begin{array}{l}\text { Neurologic morbidity and mortality } \\
\text { (all patients) }\end{array}$ & $26(9.5 \%)$ & $14(4.8 \%)$ & $9(16.4 \%)$ & $18(10.9 \%)$ & $67(8.4 \%)$ & $(6.5 \%-10.3 \%) ; .01$ \\
\hline $\begin{array}{l}\text { Neurologic morbidity and mortality } \\
\text { (patients with unruptured aneurysms) }\end{array}$ & $24 / 263(9.2 \%)$ & $11 / 270(4.1 \%)$ & $7 / 51(13.7 \%)$ & $11 / 131$ (8.4\%) & $53 / 717(7.4 \%)$ & $(5.5 \%-9.3 \%) ; .03$ \\
\hline $\begin{array}{l}\text { Neurologic morbidity and mortality } \\
\text { (patients with ruptured aneurysms) }\end{array}$ & 2/12 (16.7\%) & $3 / 24$ (12.5\%) & 2/4 (50.0\%) & $7 / 34$ (20.6\%) & $14 / 76$ (18.4\%) & (10.0\%-27.1\%); 35 \\
\hline $\begin{array}{l}\text { Neurologic morbidity and mortality } \\
\text { (excluding ruptured, dissecting, or } \\
\text { fusiform aneurysms) }\end{array}$ & $15(7.0 \%)$ & $9(3.6 \%)$ & $3(12.0 \%)$ & $6(6.8 \%)$ & 33 (5.7\%) & $(4.1 \%-7.3 \%) ; .19$ \\
\hline
\end{tabular}

Note: $-n$ indicates the number of patients.

${ }^{a}$ Numbers do not sum across categories and subcategories because some patients experienced $>1$ event.

Table 3: Occurrence of complications by time

\begin{tabular}{|c|c|c|c|c|c|c|c|c|}
\hline \multirow[b]{2}{*}{ Complications } & \multicolumn{2}{|c|}{$<72$ Hours } & \multicolumn{2}{|c|}{72 Hours-30 Days } & \multicolumn{2}{|c|}{ >30 Days } & \multirow[b]{2}{*}{$\begin{array}{c}\text { Total } \\
(n=793)^{\mathrm{a}}\end{array}$} & \multirow[b]{2}{*}{$\begin{array}{c}P \\
\text { Value }\end{array}$} \\
\hline & $\begin{array}{l}\text { Anterior } \\
(n=738)\end{array}$ & $\begin{array}{l}\text { Posterior } \\
(n=55)\end{array}$ & $\begin{array}{l}\text { Anterior } \\
(n=738)\end{array}$ & $\begin{array}{l}\text { Posterior } \\
(n=55)\end{array}$ & $\begin{array}{l}\text { Anterior } \\
(n=738)\end{array}$ & $\begin{array}{l}\text { Posterior } \\
(n=55)\end{array}$ & & \\
\hline Spontaneous rupture & $1(0.1 \%)$ & $0(0 \%)$ & $3(0.4 \%)$ & $0(0 \%)$ & $1(0.1 \%)$ & $0(0 \%)$ & $5(0.6 \%)$ & .51 \\
\hline Intraparenchymal hemorrhage & $3(0.4 \%)$ & $1(1.8 \%)$ & $11(1.5 \%)$ & $0(0 \%)$ & $4(0.5 \%)$ & $0(0 \%)$ & $19(2.4 \%)$ & .83 \\
\hline Ischemic stroke & $17(2.3 \%)$ & $2(3.6 \%)$ & $7(0.9 \%)$ & $0(0 \%)$ & $9(1.2 \%)$ & $2(3.6 \%)$ & $37(4.7 \%)$ & .58 \\
\hline Parent artery stenosis & $0(0 \%)$ & $0(0 \%)$ & $1(0.1 \%)$ & $0(0 \%)$ & $1(0.1 \%)$ & $0(0 \%)$ & $2(0.3 \%)$ & .63 \\
\hline Cranial neuropathy & $0(0 \%)$ & $0(0 \%)$ & $2(0.3 \%)$ & $0(0 \%)$ & $0(0 \%)$ & $0(0 \%)$ & $2(0.3 \%)$ & .58 \\
\hline Neurologic morbidity & $20(2.7 \%)$ & $3(5.5 \%)$ & $21(2.8 \%)$ & $0(0 \%)$ & $13(1.8 \%)$ & $2(3.6 \%)$ & $59(7.4 \%)$ & .56 \\
\hline Neurologic mortality & $4(0.5 \%)$ & $1(1.8 \%)$ & $13(1.8 \%)$ & $2(3.6 \%)$ & $7(0.9 \%)$ & $3(5.5 \%)$ & $30(3.8 \%)$ & $<.01$ \\
\hline $\begin{array}{l}\text { Neurologic morbidity and mortality } \\
\text { (all patients) }\end{array}$ & $23(3.1 \%)$ & $3(5.5 \%)$ & $22(3.0 \%)$ & $2(3.6 \%)$ & $13(1.8 \%)$ & $4(7.3 \%)$ & $67(8.4 \%)$ & $<.01$ \\
\hline $\begin{array}{l}\text { Neurologic morbidity and mortality } \\
\text { (patients with unruptured aneurysms) }\end{array}$ & $19 / 664$ (2.9\%) & $3 / 51(5.9 \%)$ & $16 / 664(2.4 \%)$ & $1 / 51(2.0 \%)$ & 11/664 (1.7\%) & $3 / 51(5.9 \%)$ & $53 / 717(7.4 \%)$ & .08 \\
\hline $\begin{array}{l}\text { Neurologic morbidity and mortality } \\
\text { (patients with ruptured aneurysms) }\end{array}$ & 4/70 (5.7\%) & $0 / 4(0 \%)$ & $6 / 70(8.6 \%)$ & $1 / 4(25.0 \%)$ & $2 / 70(2.9 \%)$ & $1 / 4(25.0 \%)$ & 14/76 (18.4\%) & .17 \\
\hline $\begin{array}{l}\text { Neurologic morbidity and mortality } \\
\text { (excluding ruptured, dissecting, or } \\
\text { fusiform aneurysms) }\end{array}$ & $13 / 549(2.4 \%)$ & $1 / 25(4.0 \%)$ & $12 / 549(2.2 \%)$ & $0 / 25(0 \%)$ & $5 / 549(0.9 \%)$ & $2 / 25(8.0 \%)$ & $33 / 575$ (5.7\%) & .41 \\
\hline
\end{tabular}

Note: $-n$ indicates the number of patients.

${ }^{a}$ Numbers do not sum across categories and subcategories because some patients experienced $>1$ event.

highest stroke rates were seen in patients with posterior circulation aneurysms $(7.3 \%, 4 / 55)$ and the "other anterior circulation" group $(6.1 \%, 10 / 165)$. The anterior circulation ICA $<10-\mathrm{mm}$ group had the lowest stroke rates $(2.7 \%, 8 / 294)(P=.16)$. When studying differences based on aneurysm size, patients with giant aneurysms had the highest stroke rates $(14.5 \%, 9 / 62)$ compared with patients with large $(5.0 \%, 17 / 339)$ and small aneurysms $(2.8 \%, 11 / 386)(P<.01)$.

In-stent stenosis occurred in $0.3 \%(2 / 793)$ with no significant differences among groups $(P=1.0)$. Permanent cranial neuropathy occurred in $0.3 \%(2 / 793)$ of patients with no significant differences among groups $(P=.30)$. These data are summarized in Tables 2-4.

Neurologic mortality was 3.8\% (30/793) and was significantly different among the 4 primary patient subgroups $(P<.01)$. The 30 -day mortality rate was $2.5 \%$ (20/793), which represented nearly two-thirds of all mortality observed in the average 19.3 months of follow-up. Patients with posterior circulation aneurysms had the highest rate of neurologic mortality $(10.9 \%, 6 / 55)$, and patients with anterior ICA $<10$-mm aneurysms had the low- est neurologic mortality $(1.4 \%, 4 / 294)$. The mortality rate was significantly higher in patients with giant aneurysms compared with those with large and small aneurysms, respectively $(9.6 \%$ versus $5.0 \%$ versus $1.8 \%, P<.01)$. The overall mortality rate in patients who presented with ruptured aneurysms was $10.5 \%(8 /$ $76)$, with no significant differences among groups $(P=.11)$. These data are summarized in Tables 2-4.

In addition to the above-listed major events, 5 cases of intracranial hemorrhage, 15 cases of ischemic strokes, and 5 cases of parent artery stenosis were also observed as minor events in which the patient's symptoms resolved within 7 days of the event occurrence with no clinical sequelae. Three additional deaths were reported due to non-neurologic reasons.

\section{DISCUSSION}

This large multicenter study of flow-diversion therapy demonstrated a neurologic morbidity and mortality rate of $8.4 \%$. Most adverse events were ischemic strokes from thromboembolic complications and were substantially more common in large, anterior circulation aneurysms and posterior circulation aneurysms com- 
Table 4: Complications by aneurysm size

\begin{tabular}{|c|c|c|c|c|c|c|c|c|}
\hline \multirow[b]{2}{*}{ Complications } & \multicolumn{2}{|c|}{ Small $(n=386)(N=473)$} & \multicolumn{2}{|c|}{ Large $(n=339)(N=357)$} & \multicolumn{2}{|c|}{ Giant $(n=62)(N=66)$} & \multirow[b]{2}{*}{$\begin{array}{l}\text { Total }(n=793)^{\mathrm{a}, \mathrm{b}} \\
(N=906)\end{array}$} & \multirow[b]{2}{*}{$\begin{array}{c}P \\
\text { Value }\end{array}$} \\
\hline & $\begin{array}{l}\text { Anterior } \\
(n=372)\end{array}$ & $\begin{array}{l}\text { Posterior } \\
(n=14)\end{array}$ & $\begin{array}{l}\text { Anterior } \\
(n=309)\end{array}$ & $\begin{array}{l}\text { Posterior } \\
(n=30)\end{array}$ & $\begin{array}{l}\text { Anterior } \\
(n=52)\end{array}$ & $\begin{array}{l}\text { Posterior } \\
(n=10)\end{array}$ & & \\
\hline Mean aneurysm size (mm) & $5.1 \pm 2.2$ & $6.0 \pm 2.6$ & $14.8 \pm 4.0$ & $15.0 \pm 4.3$ & $28.8 \pm 5.3$ & $29.1 \pm 7.2$ & $10.7 \pm 7.7$ & $<.001$ \\
\hline Spontaneous rupture & $0(0 \%)$ & $0(0 \%)$ & $2(0.5 \%)$ & $0(0 \%)$ & $3(5.8 \%)$ & $0(0 \%)$ & $5(0.6 \%)$ & $<.01$ \\
\hline Intraparenchymal hemorrhage & $7(1.9 \%)$ & $0(0 \%)$ & $8(2.6 \%)$ & $0(0 \%)$ & $3(5.8 \%)$ & $1(10.0 \%)$ & $19(2.4 \%)$ & .24 \\
\hline Ischemic stroke & $10(2.7 \%)$ & $1(7.1 \%)$ & $16(5.2 \%)$ & $1(3.3 \%)$ & $7(13.5 \%)$ & $2(20.0 \%)$ & $37(4.7 \%)$ & $<.01$ \\
\hline Parent artery stenosis & $1(0.3 \%)$ & $0(0 \%)$ & $1(0.3 \%)$ & $0(0 \%)$ & $0(0 \%)$ & $0(0 \%)$ & $2(0.3 \%)$ & 1.0 \\
\hline Cranial neuropathy & $0(0 \%)$ & $0(0 \%)$ & $2(0.6 \%)$ & $0(0 \%)$ & $0(0 \%)$ & $0(0 \%)$ & $2(0.3 \%)$ & .41 \\
\hline Neurologic morbidity & $18(4.8 \%)$ & $1(7.1 \%)$ & $24(7.8 \%)$ & $1(3.3 \%)$ & $12(23.1 \%)$ & $3(30.0 \%)$ & 59 (7.4\%) & $<.01$ \\
\hline Neurologic mortality & $6(1.6 \%)$ & $1(7.1 \%)$ & $15(4.9 \%)$ & $2(6.7 \%)$ & $3(5.8 \%)$ & $3(30.0 \%)$ & $30(3.8 \%)$ & $<.01$ \\
\hline $\begin{array}{l}\text { Neurologic morbidity and mortality }{ }^{a} \\
\text { (all patients) }\end{array}$ & $19(5.1 \%)$ & $2(14.3 \%)$ & $27(8.7 \%)$ & $3(10.0 \%)$ & $12(23.1 \%)$ & $4(40.0 \%)$ & $67(8.4 \%)$ & $<.01$ \\
\hline $\begin{array}{l}\text { Neurologic morbidity and mortality } \\
\text { (patients with unruptured aneurysms) }\end{array}$ & $11 / 321(3.4 \%)$ & $1 / 12(8.3 \%)$ & 23/291 (7.9\%) & $3 / 29(10.3 \%)$ & $12 / 51(23.5 \%)$ & $3 / 9(33.3 \%)$ & $53 / 717(7.4 \%)$ & $<.01$ \\
\hline $\begin{array}{l}\text { Neurologic morbidity and mortality } \\
\text { (patients with ruptured aneurysms) }\end{array}$ & $8 / 51(15.7 \%)$ & $1 / 2(50.0 \%)$ & $4 / 18(22.2 \%)$ & $0 / 1(0 \%)$ & $0 / 1(0 \%)$ & $1 / 1(100 \%)$ & $14 / 76$ (18.4\%) & .23 \\
\hline $\begin{array}{l}\text { Neurologic morbidity and mortality } \\
\text { (excluding ruptured, dissecting, or } \\
\text { fusiform aneurysms) }\end{array}$ & $11 / 294(3.7 \%)$ & $0 / 7(0 \%)$ & $12 / 217(5.5 \%)$ & $2 / 13(15.4 \%)$ & $7 / 37(18.9 \%)$ & $1 / 5(20.0 \%)$ & $33 / 574(5.7 \%)$ & $<.01$ \\
\hline
\end{tabular}

Note: $-n$ indicates the number of patients; $N$, number of aneurysms.

a Six patients did not have aneurysm size reported.

${ }^{\mathrm{b}}$ Numbers do not sum across categories because some patients experienced $>1$ event.

pared with small, anterior circulation aneurysms. Spontaneous aneurysm rupture was rare, occurring in $0.6 \%$ of patients, with $3 / 5$ events occurring within giant aneurysms. Intraparenchymal hemorrhage, unrelated to rupture of the target aneurysm but resulting in major neurologic deficit, was noted in $2.4 \%$ of patients. These results are important because they provide clarity regarding the previously noted severe and unexpected adverse events associated with flow-diversion therapy in a real-world setting. Our data suggest strongly that spontaneous aneurysm rupture is not of clinical concern in non-giant aneurysms. Parenchymal hemorrhage remains of concern, especially because its etiology is unclear.

Our findings corroborate those of numerous previously published smaller studies and meta-analyses. Previously published studies have demonstrated morbidity and mortality rates ranging from $0 \%-12 \%$ and $0 \%-7 \%$, respectively. ${ }^{30-32}$ Two large metaanalyses of flow-diverter treatment demonstrated morbidity rates of $5.0 \%-7.3 \%$ and mortality rates of $2.8 \%-4.0 \%$. $^{1,3}$ Our study, which is the largest clinical study of PED to date to our knowledge, demonstrated a 30-day morbidity rate of 5.5\% (44/793) and a 30 -day mortality rate of $2.5 \%$ (20/793).

Posttreatment aneurysm rupture is a serious concern of flowdiverter therapy. Concerns for postoperative aneurysm rupture with flow diverters are so serious that Balt Extrusion issued a medical device alert instructing practitioners not to use the Silk flow diverter (Balt Extrusion, Montmorency, France) without coils due to the "potential for patient death." ${ }^{13}$ In their metaanalysis of flow-diverter treatment, which included the PED and Silk flow-diverter devices, Brinjikji et $\mathrm{al}^{3}$ found an overall postoperative rupture rate of $4 \%$, with an early rupture rate of $3 \%$ with a significantly higher rupture rate in large and giant aneurysms. Our study demonstrated a posttreatment rupture rate of $<1 \%$, $3 / 5$ occurring among patients with giant aneurysms. While postoperative rupture rates are minimal in patients with small and large aneurysms, postoperative rupture remains a real and significant complication of Pipeline treatment in patients with giant aneurysms.

Spontaneous IPH is a poorly understood complication of flow-diverter treatment. Hemorrhagic transformation of ischemic stroke, hemodynamic alteration from flow-diverter placement, dual antiplatelet therapy, potential association with intraprocedural foreign body emboli, and the significant role of P2Y12 receptor overinhibition are proposed mechanisms. ${ }^{8,14,15,33}$ Prior studies have reported rates ranging from $0 \%$ to $10 \%$ for this complication. ${ }^{8,30,34,35}$ In their meta-analysis, Brinjikji et $\mathrm{al}^{3}$ found an IPH rate of $3.0 \%$. Arrese et $\mathrm{al}^{1}$ found a postoperative hemorrhage rate of $1.8 \%$, not stratifying by SAH and IPH. Our study found an IPH rate of $2.4 \%$. Similar to prior studies, our study found no difference in IPH rates by aneurysm size or location. ${ }^{3}$

Ischemic strokes due to thromboembolism and perforator infarctions are well-described complications of flow-diverter treatment. Ischemic stroke may result from stent wall thrombus formation and occlusion, parent artery occlusion, or distal thromboembolic events. Our study found an ischemic stroke rate of $4.7 \%$, with higher rates in posterior circulation aneurysms compared with the ICA aneurysm $<10$-mm group (7.3\% versus $2.7 \%){ }^{1,3,9,36}$ Similar to Brinjikji et al, ${ }^{3}$ we also found that the stroke rate increased with aneurysm size as patients with large and giant aneurysms had higher stroke rates than those with small aneurysms. Intraoperatively, acute thrombus formation can be mitigated by prompt injection of glycoprotein IIb/IIIa platelet inhibitors; however, it is difficult to reduce the long-term risk of thromboembolic events associated with flow-diverter treatment. ${ }^{37}$

Endosaccular coiling (with or without stent assistance) is an alternative to flow-diverter therapy. A systematic review of stentassisted coiling by McLaughlin et $\mathrm{al}^{38}$ found an intraprocedural complication rate of $4.0 \%$, a postprocedural thromboembolic event rate of $4.3 \%$, and a delayed in-stent stenosis rate of $5.3 \%$. These complication rates are similar to the findings of our study on the PED. In a study of stent-assisted coiling in patients with subarachnoid hemorrhage, Bodily et $\mathrm{al}^{39}$ found a clinically significant thromboembolic event rate of $6 \%$. A meta-analysis by Shapiro et $\mathrm{al}^{40}$ found that the overall procedural complication rate associated with stent coiling was $19 \%$, the thromboembolic complication rate was $10 \%$, and the periprocedural mortality was 
$2.1 \%$. In the Neuroform stent (Stryker Neurovascular, Kalamazoo, Michigan) experience in 284 patients, Fiorella et $\mathrm{al}^{41}$ reported a cumulative ischemic stroke rate of $8.8 \%$ and a $2.8 \%$ neurovascular death rate. They also reported that $15.1 \%$ of the cases had major recanalization requiring retreatment. Piotin et $\mathrm{al}^{42}$ reported results on the treatment of aneurysms with coils, with and without stents, in 1137 patients. The rate of permanent neurologic procedure-related complications was $7.4 \%$ of the procedures with stents versus $3.8 \%$ in the procedures without stents $(P=.64)$. Procedure-induced mortality occurred in $4.6 \%$ of the procedures with stents versus $1.2 \%$ in the procedures without stents $(P=.006)$. The rate of thrombotic complications in the stent group was $14.8 \%$, accounting for $11.1 \%$ of mortalities. ${ }^{42}$ Retrospective studies comparing flow diversion with the PED with coiling (with and without stent assistance) have demonstrated that the PED provides higher aneurysm occlusion rates with similar morbidity and mortality rates. ${ }^{23,43}$ In our study, anterior circulation aneurysms measuring $<10 \mathrm{~mm}$ had the lowest neurologic morbidity and mortality rates $(4.8 \%)$. These findings corroborate those of a previous study comparing the PED with stent-assisted coiling of patients with small, unruptured anterior circulation aneurysms, which demonstrated a complication rate of $5 \%$ in the PED group and 3\% in the stent-assisted coiling group. ${ }^{43}$ Given the wide range of treatment options available for the endovascular treatment of intracranial aneurysms, careful study and stratification of outcomes by aneurysm location and size are recommended to determine the best treatment for each patient. Ultimately, further comparative studies, especially in the case of small ICA aneurysms, are needed to determine which subsets of intracranial aneurysms would benefit most from PED placement compared with endosaccular coiling.

\section{Limitations}

Our study has limitations. It was a retrospective study in which sites followed their standard of practice for treating aneurysms with PED, and there was a wide range of treatment regimens (eg, antiplatelet therapy) among centers. However, all study adverse events collected were prespecified in the study protocol and were adjudicated by the Adverse Events Review Committee to maintain consistency in the study results. Patients who underwent failed embolization or who did not have follow-up were excluded per the study design. There was no systematic imaging of patients required in this study because sites were required to follow their standard procedures. There was no protocol regarding the minimum duration of follow-up, and follow-up timing was per standard of care for the treating physician and institution. Another limitation of the study is that the reporting of major and minor complications was based on the duration of symptoms, not their severity or degree of disability. Information regarding management of the major and minor complications was not collected. A broad range of aneurysm types and sizes was included in this registry (ie, saccular/blister/ruptured/fusiform/dissecting), and subgroup analyses were not performed for the subset of blister/ fusiform/dissecting aneurysms in this study. Last, 38\% of these patients had been included in prior publications.

\section{CONCLUSIONS}

Our study suggests that the treatment of intracranial aneurysms with PED is associated with the lowest complication rates when used to treat small aneurysms of the ICA. The rates of proceduralrelated morbidity and mortality are not negligible. Patients with posterior circulation aneurysms and giant aneurysms are at higher risk of ischemic stroke. Patients with large or giant aneurysms are at higher risk of ischemic stroke and SAH compared with small aneurysms. The neurologic morbidity and mortality rate drops when patients with difficult-to-treat aneurysms (ruptured, dissecting, or fusiform) are excluded. The complication rates with $\mathrm{PED}$ are comparable with those of other endovascular treatment options such as stent-assisted coiling. These findings should be considered when selecting the best therapeutic option for intracranial aneurysms.

Disclosures: David F. Kallmes_RELATED: Grant: ev3/Covidien, * Comments: funding for enrollment in clinical trial; Consulting Fee or Honorarium: ev3/Covidien, ${ }^{*} \mathrm{Com}$ ments: funding for Principal Investigator duties, Steering Committee and Adverse Event Adjudication Committee; Grants/Grants Pending: MicroVention,* ev3/Covidien, ${ }^{*}$ SurModics, ${ }^{*}$ Codman, ${ }^{*}$ Sequent Medical, ${ }^{*}$ Benvenue Medical, ${ }^{*}$ National Institutes of Health, ${ }^{*}$ Comments: funding for preclinical research and clinical trials; Royalties: University of Virginia Patent Foundation, Comments: spinal fusion; Other: Radiological Society of North America, Comments: editorial support money to institution. Demetrius Lopes-RELATED: Board Membership: Covidien (advisory board); Consultancy: Covidien; Grant: Covidien; Payment for Lectures (including service on Speakers Bureaus, papers, and teaching): Covidien; Other: Covidien (proctorship, advisory board). Edoardo Boccardi-RELATED: Consulting Fee or Honorarium: Covidien; Support for Travel to Meetings for the Study or Other Purposes: Covidien; UNRELATED: Consultancy: Covidien, Comments: consultation and proctoring. Saruhan Cekirge-RELATED: Consulting Fee or Honorarium: Covidien; UNRELATED: Consultancy: MicroVention, Covidien, Sequent. Pascal JabbourUNRELATED: Consultancy: Covidien. Cameron MCDougall—RELATED: Consulting Fee or Honorarium: ev3/Covidien; Fees for Participation in Review Activities such as Data Monitoring Boards, Statistical Analysis, Endpoint Committees, and the Like: ev3/Covidien (steering committee, medical advisory board); UNRELATED: Board Membership: ev3/Covidien; Consultancy: MicroVention/Terumo, Codman/Johnson and Johnson; Personal Fees: MicroVention (principal investigator, FRED). Adnan Siddiqui-UNRELATED: Board Membership: Codman \& Shurtleff, Covidien, Comments: advisory board; Consultancy: Codman \& Shurtleff, Concentric Medical, ev3/ Covidien, GuidePoint Global, Penumbra, Stryker, Pulsar Vascular, MicroVention, Lazarus Effect, Blockade Medical, Comments: no consulting salary arrangements; all consulting is per project and/or per hour; Grants/Grants Pending: National Institutes of Health (coinvestigator: National Institute of Neurological Disorders and Stroke 1R01NS064592-01A1, hemodynamic induction of pathologic remodeling leading to intracranial aneurysms), ${ }^{*}$ University at Buffalo (Research Development Award), ${ }^{\star}$ National Institutes of Health (coinvestigator: National Institute of Biomedical Imaging and Bioengineering 5 R01 EB002873-07, Micro-Radiographic Image for Neurovascular Interventions) ${ }^{\star}$; National Steering Committees: Penumbra (3D Separator Trial), Covidien (SWIFT PRIME Trial), MicroVention (FRED Trial); Payment for Lectures (including service on speakers bureaus): Codman \& Shurtleff; Stock/Stock Options: Hotspur, Intratech Medical, StimSox, Valor Medical, Blockade Medical, Lazarus Effect; Other: Abbott Vascular, Penumbra, Abbott Vascular, and Codman \& Shurtleff (for training other neurointerventionists in carotid stenting and for training physicians in endovascular stenting for aneurysms), Comments: honoraria. Henry Woo-RELATED: Other: Covidien, * Comments: startup costs for institutional review board submission and payment for enrolled patients; UNRELATED: Grants/Grants Pending: Siemens, ${ }^{*}$ Comments: grants for clinical and academic research; Royalties: Codman \& Shurtleff, Comments: royalties for development of intellectual property; Other: shareholder in Vascular Simulators. Britton K. Woodward-UNRELATED: Personal Fees: Covidien, Comments: consultant for proctoring of cases. Shervin R. Dashti-UNRELATED: Other: proctoring fees from Covidien, MicroVention. Josser E. Delgado Almandoz-RELATED: Personal Fees: Covidien/ev3; UNRELATED: Personal Fee: Terumo/MicroVention. Istvan Szikora — RELATED: Grant: Covidien; Personal Fees: Covidien. Elad Levy_UNRELATED: Shareholder/Ownership Interest: Intratech Medical Ltd, Mynx Access Closure, Blockade Medical LLC. Alain Bonafé-UNRELATED: Personal Fees: Covidien (proctoring for PED). Michael E. Kelly—RELATED: Other: Covidien sponsored the IntrePED study, and all funds were paid to University of Saskatchewan. Raymond Turner-RELATED: Grants: Covidien, MicroVention, Codman, Blockade Medical, Reverse Medical; Personal Fees: Covidien, MicroVention, Codman, Blockade Medical, Pulsar Vascular. David Fiorella_UNRELATED: Grants: Siemens, MicroVention; Personal 
Fees: Covidien/ev3, Cordis, Nfocus Neuromedical, Micrus Endovascular, Comments: Consultant; Royalties: Codman \& Shurtleff (Revive); Ownership Interests: Vascular Simulators LLC, TDC Technologies, CVSL. Giuseppe Lanzino-UNRELATED: Consultancy: Edge Therapeutics, Covidien/ev3, Codman. Pedro Lylyk—UNRELATED: Consultancy: ev3, MicroVention, Covidien, Codman; Payment for Lectures (including service on Speakers Bureaus): Covidien, MicroVention, Codman. Ricardo Hanel—RELATED: Grant: MicroVention; UNRELATED: Consultancy: Covidien, Codman, Stryker; Other: Blockade (shareholder). *Money paid to the institution.

\section{REFERENCES}

1. Arrese I, Sarabia R, Pintado R, et al. Flow-diverter devices for intracranial aneurysms: systematic review and meta-analysis. Neurosurgery 2013;73:193-99; discussion 199-200

2. Briganti F, Napoli M, Tortora F, et al. Italian multicenter experience with flow-diverter devices for intracranial unruptured aneurysm treatment with periprocedural complications: a retrospective data analysis. Neuroradiology 2012;54:1145-52

3. Brinjikji W, Murad MH, Lanzino G, et al. Endovascular treatment of intracranial aneurysms with flow diverters: a meta-analysis. Stroke 2013;44:442-47

4. Yu SC, Kwok CK, Cheng PW, et al. Intracranial aneurysms: midterm outcome of Pipeline embolization device: a prospective study in 143 patients with 178 aneurysms. Radiology 2012;265:893-901

5. Chan TT, Chan KY, Pang PK, et al. Pipeline embolisation device for wide-necked internal carotid artery aneurysms in a hospital in Hong Kong: preliminary experience. Hong Kong Med J 2011;17:398-404

6. Cirillo L, Dall'Olio M, Princiotta C, et al. The use of flow-diverting stents in the treatment of giant cerebral aneurysms: preliminary results. Neuroradiol J 2010;23:220-24

7. Siddiqui AH, Kan P, Abla AA, et al. Complications after treatment with Pipeline embolization for giant distal intracranial aneurysms with or without coil embolization. Neurosurgery 2012;71:E509-13; discussion E513

8. Cruz JP, Chow M, O’Kelly C, et al. Delayed ipsilateral parenchymal hemorrhage following flow diversion for the treatment of anterior circulation aneurysms. AJNR Am J Neuroradiol 2012;33:603-08

9. Pierot L. Flow diverter stents in the treatment of intracranial aneurysms: where are we? J Neuroradiol 2011;38:40-46

10. Darsaut TE, Rayner-Hartley E, Makoyeva A, et al. Aneurysm rupture after endovascular flow diversion: the possible role of persistent flows through the transition zone associated with device deformation. Interv Neuroradiol 2013;19:180-85

11. Kuzmik GA, Williamson T, Ediriwickrema A, et al. Flow diverters and a tale of two aneurysms. J Neurointerv Surg 2013;5:e23

12. Turowski B, Macht S, Kulcsar Z, et al. Early fatal hemorrhage after endovascular cerebral aneurysm treatment with a flow diverter (SILK-Stent): do we need to rethink our concepts? Neuroradiology 2011;53:37-41

13. Lubicz B, Collignon L, Raphaeli G, et al. Flow-diverter stent for the endovascular treatment of intracranial aneurysms: a prospective study in 29 patients with 34 aneurysms. Stroke 2010;41:2247-53

14. Piano M, Valvassori L, Quilici L, et al. Midterm and long-term follow-up of cerebral aneurysms treated with flow diverter devices: a single-center experience. J Neurosurg 2013;118:408-16

15. Delgado Almandoz JE, Crandall BM, Scholz JM, et al. Pre-procedure $\mathrm{P} 2 \mathrm{Y} 12$ reaction units value predicts perioperative thromboembolic and hemorrhagic complications in patients with cerebral aneurysms treated with the Pipeline embolization device. J Neurointerv Surg 2013;5(suppl 3):iii3-10

16. Delgado Almandoz JE, Crandall BM, Scholz JM, et al. Last-recorded $\mathrm{P} 2 \mathrm{Y} 12$ reaction units value is strongly associated with thromboembolic and hemorrhagic complications occurring up to 6 months after treatment in patients with cerebral aneurysms treated with the Pipeline embolization device. AJNR Am J Neuroradiol 2014;35:128-35

17. Hanel RA, Taussky P, Dixon T, et al. Safety and efficacy of ticagrelor for neuroendovascular procedures: a single center initial experience. J Neurointerv Surg 2014;6:320-22
18. el-Chalouhi N, Jabbour PM, Tjoumakaris SI, et al. Treatment of large and giant intracranial aneurysms: cost comparison of flow diversion and traditional embolization strategies. World Neurosurg 2014;82:696-701

19. Chalouhi N, McMahon JF, Moukarzel LA, et al. Flow diversion versus traditional aneurysm embolization strategies: analysis of fluoroscopy and procedure times. J Neurointervent Surg 2014;6:291-95

20. Chalouhi N, Tjoumakaris S, Dumont AS, et al. Treatment of posterior circulation aneurysms with the Pipeline embolization device. Neurosurgery 2013;72:883-89

21. Jabbour P, Chalouhi N, Tjoumakaris S, et al. The Pipeline embolization device: learning curve and predictors of complications and aneurysm obliteration. Neurosurgery 2013;73:113-20

22. Chitale R, Gonzalez LF, Randazzo C, et al. Single center experience with Pipeline stent: feasibility, technique, and complications. $\mathrm{Neu}$ rosurgery 2012;71:679-91

23. Chalouhi N, Tjoumakaris S, Starke RM, et al. Comparison of flow diversion and coiling in large unruptured intracranial saccular aneurysms. Stroke 2013;44:2150-54

24. O'Kelly CJ, Spears J, Chow M, et al. Canadian experience with the Pipeline embolization device for repair of unruptured intracranial aneurysms. AJNR Am J Neuroradiol 2013;34:381-87

25. Cruz JP, O'Kelly C, Kelly M, et al. Pipeline embolization device in aneurysmal subarachnoid hemorrhage. AJNR Am J Neuroradiol 2013;34:271-76

26. Kan P, Siddiqui AH, Veznedaroglu E, et al. Early postmarket results after treatment of intracranial aneurysms with the Pipeline embolization device: A US multicenter experience. Neurosurgery 2012;71:1080-87

27. Siddiqui AH, Abla AA, Kan P, et al. Panacea or problem: flow diverters in the treatment of symptomatic large or giant fusiform vertebrobasilar aneurysms - clinical article. J Neurosurg 2012;116:1258-66

28. de Barros Faria M, Castro RN, Lundquist J, et al. The role of the Pipeline embolization device for the treatment of dissecting intracranial aneurysms. AJNR Am J Neuroradiol 2011;32:2192-95

29. Brinjikji W, Lanzino G, Cloft HJ, et al. Patency of the posterior communicating artery after flow diversion treatment of internal carotid artery aneurysms. Clin Neurol Neurosurg 2014;120:84-88

30. Berge J, Biondi A, Machi P, et al. Flow-diverter Silk stent for the treatment of intracranial aneurysms: 1-year follow-up in a multicenter study. AJNR Am J Neuroradiol 2012;33:1150-55

31. Leonardi M, Cirillo L, Toni F, et al. Treatment of intracranial aneurysms using flow-diverting Silk stents (BALT): a single centre experience. Interv Neuroradiol 2011;17:306-15

32. Velioglu M, Kizilkilic O, Selcuk H, et al. Early and midterm results of complex cerebral aneurysms treated with Silk stent. Neuroradiology 2012;54:1355-65

33. Hu YC, Deshmukh VR, Albuquerque FC, et al. Histopathological assessment of fatal ipsilateral intraparenchymal hemorrhages after the treatment of supraclinoid aneurysms with the Pipeline embolization device. J Neurosurg 2014;120:365-74

34. Byrne JV, Beltechi R, Yarnold JA, et al. Early experience in the treatment of intra-cranial aneurysms by endovascular flow diversion: a multicentre prospective study. PLoS One 2010;5:pii: e12492

35. McAuliffe $\mathrm{W}$, Wycoco V, Rice $\mathrm{H}$, et al. Immediate and midterm results following treatment of unruptured intracranial aneurysms with the Pipeline embolization device. AJNR Am J Neuroradiol 2012;33:164-70

36. Wong GK, Kwan MC, Ng RY, et al. Flow diverters for treatment of intracranial aneurysms: current status and ongoing clinical trials. J Clin Neurosci 2011;18:737-40

37. Tähtinen OI, Manninen HI, Vanninen RL, et al. The Silk flow-diverting stent in the endovascular treatment of complex intracranial aneurysms: technical aspects and midterm results in 24 consecutive patients. Neurosurgery 2012;70:617-23; discussion 623-24

38. McLaughlin N, McArthur DL, Martin NA. Use of stent-assisted coil 
embolization for the treatment of wide-necked aneurysms: a systematic review. Surg Neurol Int 2013;4:43

39. Bodily KD, Cloft HJ, Lanzino G, et al. Stent-assisted coiling in acutely ruptured intracranial aneurysms: a qualitative, systematic review of the literature. AJNR Am J Neuroradiol 2011;32:1232-36

40. Shapiro M, Becske T, Sahlein D, et al. Stent-supported aneurysm coiling: a literature survey of treatment and follow-up. AJNR Am J Neuroradiol 2012;33:159-63

41. Fiorella D, Albuquerque FC, Woo H, et al. Neuroform stent as- sisted aneurysm treatment: evolving treatment strategies, complications and results of long term follow-up. J Neurointerv Surg 2010;2:16-22

42. Piotin M, Blanc R, Spelle L, et al. Stent-assisted coiling of intracranial aneurysms: clinical and angiographic results in 216 consecutive aneurysms. Stroke 2010;41:110-15

43. Chalouhi N, Starke RM, Yang S, et al. Extending the indications of flow diversion to small, unruptured, saccular aneurysms of the anterior circulation. Stroke 2014;45:54-58 
$\mathbf{T}$ he original versions of Tables 1-4 that were contained in the article "International Retrospective Study of the Pipeline Embolization Device: A Multicenter Aneurysm Treatment Study” by D.F. Kallmes, R. Hanel, D. Lopes et al (AJNR Am J Neuroradiol 2015;36:108-15, originally published on-line on October 29, 2014, 10.3174/ajnr.A4111) contained errors. Due to a coding problem, 36 PICA and vertebral artery aneurysms were changed from "anterior" to "posterior." In addition, 17 ICA aneurysms were changed from "other anterior" to "ICA." The authors state that these changes do not affect the conclusions or clinical implications of their paper. The only outcome that changed in statistical significance was the comparison of the rates of neurologic mortality and neurologic morbidity + mortality between anterior and posterior circulation aneurysms at $>30$ days (Table 3 ). These are the corrected tables.

http://dx.doi.org/10.3174/ajnr.A4307

Table 1: Aneurysm characteristics

\begin{tabular}{|c|c|c|c|c|c|c|}
\hline Aneurysm Characteristics & $\begin{array}{l}\text { Anterior } \\
\text { ICA } \geq 10 \mathrm{~mm}\end{array}$ & $\begin{array}{l}\text { Anterior } \\
\text { ICA }<10 \mathrm{~mm}\end{array}$ & Posterior & $\begin{array}{l}\text { Other } \\
\text { Anterior }\end{array}$ & $P$ Value & Total \\
\hline Aneurysm size $(\mathrm{mm})$ & & & & & $<.0001$ & \\
\hline Mean $\pm \mathrm{SD}(n)$ & $16.8 \pm 6.3(317)$ & $5.2 \pm 2.2(360)$ & $13.8 \pm 8.4(93)$ & $9.2 \pm 8.0(126)$ & & $10.7 \pm 7.7(896)$ \\
\hline Median, range & $15.0,10.0-42.0$ & $5.0,1.0-10.0$ & $11.6,1.5-45.0$ & $6.7,1.0-55.0$ & & $9.0,1.0-55.0$ \\
\hline Aneurysm type & & & & & $<.0001$ & \\
\hline Small & $0.0 \%(0 / 317)$ & $100.0 \%(360 / 360)$ & $35.5 \%(33 / 93)$ & $63.5 \%(80 / 126)$ & & $52.8 \%(473 / 896)$ \\
\hline Large & $85.8 \%(272 / 317)$ & $0.0 \%(0 / 360)$ & $49.5 \%(46 / 93)$ & $31.0 \%(39 / 126)$ & & $39.8 \%(357 / 896)$ \\
\hline Giant & $14.2 \%(45 / 317)$ & $0.0 \%(0 / 360)$ & $15.1 \%(14 / 93)$ & $5.6 \%(7 / 126)$ & & $7.4 \%(66 / 896)$ \\
\hline Aneurysm neck (mm) & & & & & $<.0001$ & \\
\hline Mean $\pm \mathrm{SD}(n)$ & $8.5 \pm 5.0(297)$ & $4.1 \pm 2.2(335)$ & $8.7 \pm 7.5(70)$ & $4.8 \pm 5.1(110)$ & & $6.2 \pm 4.9(812)$ \\
\hline Median, range & $7.6,0.9-50.0$ & $3.9,0.8-22.0$ & $6.6,1.7-53.0$ & $3.9,1.0-50.0$ & & $5.0,0.8-53.0$ \\
\hline Aneurysm shape & & & & & $<.0001$ & \\
\hline Saccular & $77.3 \%(245 / 317)$ & $87.8 \%(316 / 360)$ & $35.8 \%(34 / 95)$ & $71.7 \%(91 / 127)$ & & $76.0 \%(689 / 906)$ \\
\hline Fusiform & $15.5 \%(49 / 317)$ & $4.7 \%(17 / 360)$ & $29.5 \%(28 / 95)$ & $15.0 \%(19 / 127)$ & & $12.8 \%(116 / 906)$ \\
\hline Dissecting & $3.2 \%(10 / 317)$ & $2.2 \%(8 / 360)$ & $28.4 \%(27 / 95)$ & $7.1 \%(9 / 127)$ & & $6.0 \%(54 / 906)$ \\
\hline Other & $4.1 \%(13 / 317)$ & $5.3 \%(19 / 360)$ & $6.3 \%(6 / 95)$ & $6.3 \%(8 / 127)$ & & $5.2 \%(47 / 906)$ \\
\hline Aneurysm location & & & & & $<.0001$ & \\
\hline Internal carotid artery & $100.0 \%(317 / 317)$ & $100.0 \%(360 / 360)$ & $0.0 \%(0 / 95)$ & $0.0 \%(0 / 127)$ & & $75.5 \%(684 / 906)$ \\
\hline Middle cerebral artery & $0.0 \%(0 / 317)$ & $0.0 \%(0 / 360)$ & $0.0 \%(0 / 95)$ & $33.9 \%(43 / 127)$ & & $4.7 \%(43 / 906)$ \\
\hline Posterior cerebral artery & $0.0 \%(0 / 317)$ & $0.0 \%(0 / 360)$ & $15.8 \%(15 / 95)$ & $0.0 \%(0 / 127)$ & & $1.7 \%(15 / 906)$ \\
\hline Basilar artery & $0.0 \%(0 / 317)$ & $0.0 \%(0 / 360)$ & $46.3 \%(44 / 95)$ & $0.0 \%(0 / 127)$ & & $4.9 \%(44 / 906)$ \\
\hline Other & $0.0 \%(0 / 317)$ & $0.0 \%(0 / 360)$ & $37.9 \%(36 / 95)$ & $66.1 \%(84 / 127)$ & & $13.2 \%(120 / 906)$ \\
\hline $\begin{array}{l}\text { Presented with ruptured } \\
\text { aneurysm }\end{array}$ & $3.8 \%(12 / 317)$ & $6.7 \%(24 / 360)$ & $7.4 \%(7 / 95)$ & $25.2 \%(32 / 127)$ & $<.0001$ & $8.4 \%(76 / 906)$ \\
\hline Multiple PEDs utilized & $45.4 \%(144 / 317)$ & $27.4 \%(98 / 358)$ & $37.9 \%(36 / 95)$ & $22.8 \%(29 / 127)$ & $<.0001$ & $34.1 \%(308 / 904)$ \\
\hline
\end{tabular}

Table 2: Complications by aneurysm location and size subgroups

\begin{tabular}{|c|c|c|c|c|c|c|c|}
\hline Patient Characteristics & $\begin{array}{c}\text { Anterior } \\
\text { ICA } \geqq 10 \mathrm{~mm}\end{array}$ & $\begin{array}{c}\text { Anterior } \\
\text { ICA }<10 \mathrm{~mm}\end{array}$ & Posterior & $\begin{array}{c}\text { Other } \\
\text { Anterior }\end{array}$ & $P$ Value & Total & $95 \% \mathrm{Cl}$ \\
\hline Aneurysm size (mm) & & & & & $<.0001$ & & $(10.7-11.8)$ \\
\hline Mean \pm SD $(n)$ & $16.8 \pm 6.3(296)$ & $5.3 \pm 2.2(291)$ & $14.2 \pm 8.5(88)$ & $9.7 \pm 8.3(112)$ & & $11.2 \pm 7.8(787)$ & \\
\hline Median, range & $15.0,10.0-42.0$ & $5.0,1.2-10.0$ & $12.0,1.5-45.0$ & $7.1,1.0-55.0$ & & $10.0,1.0-55.0$ & \\
\hline Spontaneous rupture & $1.4 \%(4 / 296)$ & $0.0 \%(0 / 291)$ & $1.1 \%(1 / 90)$ & $0.0 \%(0 / 112)$ & .1657 & $0.6 \%(5 / 793)$ & $(0.2 \%-1.5 \%)$ \\
\hline Intracranial hemorrhage & $2.7 \%(8 / 296)$ & $1.4 \%(4 / 291)$ & $2.2 \%(2 / 90)$ & $5.4 \%(6 / 112)$ & .2299 & $2.5 \%(20 / 793)$ & $(1.6 \%-3.9 \%)$ \\
\hline Ischemic stroke & $5.4 \%(16 / 296)$ & $2.4 \%(7 / 291)$ & $6.7 \%(6 / 90)$ & $6.3 \%(7 / 112)$ & .1726 & $4.5 \%(36 / 793)$ & $(3.2 \%-6.2 \%)$ \\
\hline Parent artery stenosis & $0.3 \%(1 / 296)$ & $0.3 \%(1 / 291)$ & $0.0 \%(0 / 90)$ & $0.0 \%(0 / 112)$ & 1.0000 & $0.3 \%(2 / 793)$ & $(0.0 \%-0.9 \%)$ \\
\hline Cranial neuropathy & $0.7 \%(2 / 296)$ & $0.0 \%(0 / 291)$ & $0.0 \%(0 / 90)$ & $0.0 \%(0 / 112)$ & .7257 & $0.3 \%(2 / 793)$ & $(0.0 \%-0.9 \%)$ \\
\hline Neurologic morbidity & $8.8 \%(26 / 296)$ & $4.1 \%(12 / 291)$ & $8.9 \%(8 / 90)$ & $11.6 \%(13 / 112)$ & .0496 & $7.4 \%(59 / 793)$ & (5.7\%-9.5\%) \\
\hline Neurologic mortality & $3.7 \%(11 / 296)$ & $1.4 \%(4 / 291)$ & $7.8 \%(7 / 90)$ & $7.1 \%(8 / 112)$ & .0108 & $3.8 \%(30 / 793)$ & $(2.6 \%-5.4 \%)$ \\
\hline $\begin{array}{l}\text { Neurologic morbidity and } \\
\text { mortality (all patients) }\end{array}$ & $9.5 \%(28 / 296)$ & $4.1 \%(12 / 291)$ & $13.3 \%(12 / 90)$ & $13.4 \%(15 / 112)$ & .0046 & $8.4 \%(67 / 793)$ & $(6.6 \%-10.6 \%)$ \\
\hline $\begin{array}{l}\text { Neurologic morbidity and } \\
\text { mortality (patients with } \\
\text { unruptured aneurysms) }\end{array}$ & $9.5 \%(27 / 285)$ & $3.4 \%(9 / 268)$ & $12.0 \%(10 / 83)$ & $9.9 \%(8 / 81)$ & .0104 & $7.5 \%(54 / 720)$ & (5.7\%-9.7\%) \\
\hline $\begin{array}{l}\text { Neurologic morbidity and } \\
\text { mortality (patients with } \\
\text { ruptured aneurysms) }\end{array}$ & $16.7 \%(2 / 12)$ & $12.5 \%(3 / 24)$ & $28.6 \%(2 / 7)$ & $21.9 \%(7 / 32)$ & .7639 & $18.4 \%(14 / 76)$ & $(10.5 \%-29.0 \%)$ \\
\hline $\begin{array}{l}\text { Neurologic morbidity and } \\
\text { mortality (excluding } \\
\text { ruptured, dissecting, or } \\
\text { fusiform aneurysms) }\end{array}$ & $7.7 \%(18 / 233)$ & $3.6 \%(9 / 253)$ & $8.6 \%(3 / 35)$ & $9.7 \%(6 / 62)$ & .1343 & $6.2 \%(36 / 585)$ & $(4.4 \%-8.4 \%)$ \\
\hline
\end{tabular}


Table 3: Occurrence of complication by time

\begin{tabular}{|c|c|c|c|c|c|c|c|c|}
\hline \multirow[b]{2}{*}{ Major Complications } & \multicolumn{2}{|c|}{$<72$ Hours } & \multicolumn{2}{|c|}{72 Hours-30 Days } & \multicolumn{2}{|c|}{ >30 Days } & \multirow[b]{2}{*}{$P$ Value } & \multirow[b]{2}{*}{ Total } \\
\hline & Anterior & Posterior & Anterior & Posterior & Anterior & Posterior & & \\
\hline Spontaneous rupture & $0.1 \%(1 / 703)$ & $0.0 \%(0 / 90)$ & $0.3 \%(2 / 703)$ & $1.1 \%(1 / 90)$ & $0.1 \%(1 / 703)$ & $0.0 \%(0 / 90)$ & .6290 & $0.6 \%(5 / 793)$ \\
\hline Intracranial hemorrhage & $0.4 \%(3 / 703)$ & $2.2 \%(2 / 90)$ & $1.6 \%(11 / 703)$ & $0.0 \%(0 / 90)$ & $0.6 \%(4 / 703)$ & $0.0 \%(0 / 90)$ & .1363 & $2.5 \%(20 / 793)$ \\
\hline Ischemic stroke & $2.1 \%(15 / 703)$ & $3.3 \%(3 / 90)$ & $0.9 \%(6 / 703)$ & $2.2 \%(2 / 90)$ & $1.3 \%(9 / 703)$ & $1.1 \%(1 / 90)$ & .1102 & $4.5 \%(36 / 793)$ \\
\hline Parent artery stenosis & $0.0 \%(0 / 703)$ & $0.0 \%(0 / 90)$ & $0.1 \%(1 / 703)$ & $0.0 \%(0 / 90)$ & $0.1 \%(1 / 703)$ & $0.0 \%(0 / 90)$ & 1.0000 & $0.3 \%(2 / 793)$ \\
\hline Cranial neuropathy & $0.0 \%(0 / 703)$ & $0.0 \%(0 / 90)$ & $0.3 \%(2 / 703)$ & $0.0 \%(0 / 90)$ & $0.0 \%(0 / 703)$ & $0.0 \%(0 / 90)$ & .3331 & $0.3 \%(2 / 793)$ \\
\hline Neurologic morbidity & $2.6 \%(18 / 703)$ & $5.6 \%(5 / 90)$ & $2.8 \%(20 / 703)$ & $2.2 \%(2 / 90)$ & $1.8 \%(13 / 703)$ & $1.1 \%(1 / 90)$ & .2757 & $7.4 \%(59 / 793)$ \\
\hline Neurologic mortality & $1.0 \%(7 / 703)$ & $3.3 \%(3 / 90)$ & $1.4 \%(10 / 703)$ & $2.2 \%(2 / 90)$ & $0.9 \%(6 / 703)$ & $2.2 \%(2 / 90)$ & .7014 & $3.8 \%(30 / 793)$ \\
\hline $\begin{array}{l}\text { Neurologic morbidity and } \\
\text { mortality (all patients) }\end{array}$ & $2.8 \%(20 / 703)$ & $5.6 \%(5 / 90)$ & $3.1 \%(22 / 703)$ & $4.4 \%(4 / 90)$ & $1.8 \%(13 / 703)$ & $3.3 \%(3 / 90)$ & .2543 & $8.4 \%(67 / 793)$ \\
\hline $\begin{array}{l}\text { Neurologic morbidity and } \\
\text { mortality (patients with } \\
\text { unruptured aneurysms) }\end{array}$ & $2.5 \%(16 / 637)$ & $6.0 \%(5 / 83)$ & $2.7 \%(17 / 637)$ & $3.6 \%(3 / 83)$ & $1.7 \%(11 / 637)$ & $2.4 \%(2 / 83)$ & .3511 & $7.5 \%(54 / 720)$ \\
\hline $\begin{array}{l}\text { Neurologic morbidity and } \\
\text { mortality (patients with } \\
\text { ruptured aneurysms) }\end{array}$ & $5.8 \%(4 / 69)$ & $0.0 \%(0 / 7)$ & $8.7 \%(6 / 69)$ & $14.3 \%(1 / 7)$ & $2.9 \%(2 / 69)$ & $14.3 \%(1 / 7)$ & .4768 & $18.4 \%(14 / 76)$ \\
\hline $\begin{array}{l}\text { Neurologic morbidity and } \\
\text { mortality (excluding } \\
\text { ruptured, dissecting, or } \\
\text { fusiform aneurysms) }\end{array}$ & $2.5 \%(14 / 550)$ & $2.9 \%(1 / 35)$ & $2.5 \%(14 / 550)$ & $2.9 \%(1 / 35)$ & $0.9 \%(5 / 550)$ & $2.9 \%(1 / 35)$ & .0934 & $6.2 \%(36 / 585)$ \\
\hline
\end{tabular}

Table 4: Complication by aneurysm size

\begin{tabular}{|c|c|c|c|c|c|c|c|c|}
\hline \multirow[b]{2}{*}{ Major Complications } & \multicolumn{2}{|c|}{ Small } & \multicolumn{2}{|c|}{ Large } & \multicolumn{2}{|c|}{ Giant } & \multirow[b]{2}{*}{$P$ Value } & \multirow[b]{2}{*}{ Total } \\
\hline & Anterior & Posterior & Anterior & Posterior & Anterior & Posterior & & \\
\hline Aneurysm size (mm) & & & & & & & $<.0001$ & \\
\hline Mean $\pm \mathrm{SD}(n)$ & $5.3 \pm 2.2(360)$ & $6.1 \pm 2.5(27)$ & $14.8 \pm 4.1(292)$ & $14.8 \pm 4.1(46)$ & $29.2 \pm 5.6(49)$ & $28.5 \pm 6.2(14)$ & & $11.3 \pm 7.7(788)$ \\
\hline Median, range & $5.0,1.0-10.0$ & $6.3,1.5-9.4$ & $14.0,10.0-24.5$ & $14.3,10.0-23.0$ & $27.0,25.0-55.0$ & $26.0,25.0-45.0$ & & $10.0,1.0-55.0$ \\
\hline Spontaneous rupture & $0.0 \%(0 / 360)$ & $0.0 \%(0 / 27)$ & $0.7 \%(2 / 292)$ & $0.0 \%(0 / 46)$ & $4.1 \%(2 / 49)$ & $7.1 \%(1 / 14)$ & .0011 & $0.6 \%(5 / 793)$ \\
\hline Intracranial hemorrhage & $1.9 \%(7 / 360)$ & $0.0 \%(0 / 27)$ & $2.7 \%(8 / 292)$ & $2.2 \%(1 / 46)$ & $6.1 \%(3 / 49)$ & $7.1 \%(1 / 14)$ & .0901 & $2.5 \%(20 / 793)$ \\
\hline Ischemic stroke & $2.8 \%(10 / 360)$ & $0.0 \%(0 / 27)$ & $4.8 \%(14 / 292)$ & $4.3 \%(2 / 46)$ & $12.2 \%(6 / 49)$ & $21.4 \%(3 / 14)$ & .0008 & $4.5 \%(36 / 793)$ \\
\hline Parent artery stenosis & $0.3 \%(1 / 360)$ & $0.0 \%(0 / 27)$ & $0.3 \%(1 / 292)$ & $0.0 \%(0 / 46)$ & $0.0 \%(0 / 49)$ & $0.0 \%(0 / 14)$ & 1.0000 & $0.3 \%(2 / 793)$ \\
\hline Cranial neuropathy & $0.0 \%(0 / 360)$ & $0.0 \%(0 / 27)$ & $0.7 \%(2 / 292)$ & $0.0 \%(0 / 46)$ & $0.0 \%(0 / 49)$ & $0.0 \%(0 / 14)$ & .3373 & $0.3 \%(2 / 793)$ \\
\hline Neurologic morbidity & $5.0 \%(18 / 360)$ & $0.0 \%(0 / 27)$ & $7.5 \%(22 / 292)$ & $6.5 \%(3 / 46)$ & $22.4 \%(11 / 49)$ & $28.6 \%(4 / 14)$ & $<.0001$ & $7.4 \%(59 / 793)$ \\
\hline Neurologic mortality & $1.7 \%(6 / 360)$ & $3.7 \%(1 / 27)$ & $4.8 \%(14 / 292)$ & $6.5 \%(3 / 46)$ & $6.1 \%(3 / 49)$ & $21.4 \%(3 / 14)$ & .0033 & $3.8 \%(30 / 793)$ \\
\hline $\begin{array}{l}\text { Neurologic morbidity and } \\
\text { mortality (all patients) }\end{array}$ & $5.3 \%(19 / 360)$ & $3.7 \%(1 / 27)$ & $8.6 \%(25 / 292)$ & $10.9 \%(5 / 46)$ & $22.4 \%(11 / 49)$ & $35.7 \%(5 / 14)$ & $<.0001$ & $8.4 \%(67 / 793)$ \\
\hline $\begin{array}{l}\text { Neurologic morbidity and } \\
\text { mortality (patients with } \\
\text { unruptured aneurysms) }\end{array}$ & $3.5 \%(11 / 311)$ & $0.0 \%(0 / 24)$ & $7.9 \%(22 / 277)$ & $11.4 \%(5 / 44)$ & $22.9 \%(11 / 48)$ & $30.8 \%(4 / 13)$ & $<.0001$ & $7.5 \%(54 / 720)$ \\
\hline $\begin{array}{l}\text { Neurologic morbidity and } \\
\text { mortality (patients with } \\
\text { ruptured aneurysms) }\end{array}$ & $16.0 \%(8 / 50)$ & $33.3 \%(1 / 3)$ & $18.8 \%(3 / 16)$ & $0.0 \%(0 / 2)$ & $50.0 \%(1 / 2)$ & $100.0 \%(1 / 1)$ & .1385 & $18.4 \%(14 / 76)$ \\
\hline $\begin{array}{l}\text { Neurologic morbidity and } \\
\text { mortality (excluding } \\
\text { ruptured, dissecting, or } \\
\text { fusiform aneurysms) }\end{array}$ & $3.8 \%(11 / 293)$ & $0.0 \%(0 / 12)$ & $6.4 \%(14 / 218)$ & $11.8 \%(2 / 17)$ & $20.5 \%(8 / 39)$ & $20.0 \%(1 / 5)$ & .0005 & $6.2 \%(36 / 585)$ \\
\hline
\end{tabular}

